\title{
Os cursos de Ciências Contábeis no Brasil e o Conteúdo das Disciplinas de Sistemas de Informação: A visão Acadêmica versus a Necessidade Prática
}

\author{
José Dutra de Oliveira Neto \\ Prof. Dr. do Depto. de Contabilidade e Atuária - FEA - Ribeirão Preto/USP \\ João Marino Junior \\ Prof. do Depto. de Contabilidade e Atuária - FEA - Ribeirão Preto/USP \\ Leonardo Teixeira Morais \\ Graduando em Ciências Contábeis pela FEA - Ribeirão Preto/USP
}

RESUMO

O presente trabalho pesquisou um grupo de contadores profissionais (não acadêmicos) da Região de Ribeirão Preto - Estado de São Paulo /Brasil e os professores dos cursos de graduação em contabilidade do Estado de São Paulo /Brasil para identificar e quantificar a importância percebida referente a diversos tópicos da área de sistemas de Informação a serem ministrados nos cursos de Ciências Contábeis.

Os resultados indicam que existem poucas divergências em relação à ênfase dada pelos acadêmicos e práticos em relação a 33 tópicos selecionados na área de Sistema de Informações. Uma vez que o conteúdo da área de Sistema de Informação está sendo considerado inadequado para os contadores profissionais (não acadêmicos), isto pode significar a necessidade de reestruturação dos cursos de graduação em Contabilidade para atender as necessidades práticas dos contadores, além de atender às expectativas dos acadêmicos.

Palavras-chave: Educação superior, Contabilidade, Sistemas de Informação.
ABSTRACT

The purpose of this study is to identify and quantify the perceived importance given to different topics from Information System field to be taught at accounting graduate Courses. A sample of 200 accounting practitioners from the Ribeirão Preto area (State of São Paulo ) and 71 professors in Accounting from the State of São Paulo Universities (Brazil) were investigated for this purpose.

The results shows that the differences in emphasis given to the 33 selected specific topics are very small. Since the content of Information System field being taught in Accounting graduate Courses is being considered inadequate for the practitioners, this might indicate the need for restructuring the Accounting graduate course to meet the practical needs of accountants and academics expectations. Implications and results will be presented here.

Key words: Accounting graduate, Accountancy, Information System. 


\section{INTRODUÇÃO}

"Existem poucas dúvidas de que o conteúdo da educação profissional dos contadores, que teve poucas mudanças nos últimos 50 anos, é inadequado para os futuros profissionais".

O relatório "AAA Committee on the Future Structure, Content, and Scope of Accounting Education," (1986, p.172) mostrou um abismo crescente entre o que os contadores fazem e o que os educadores ensinam.

No Brasil, esse cenário se repete e a demanda para reformulações no ensino contábil é uma necessidade.

Segundo Williams (1991), os problemas podem ser enumerados como sendo:

- os cursos não estão atraindo um número suficiente de alunos com qualidade;

- o currículo perdeu sua relevância;

- o curso não está desenvolvendo habilidades e atributos necessários aos alunos.

Apesar de já conhecermos esse abismo, pouco foi desenvolvido para quantificar e identificar as diferenças entre os acadêmicos e práticos. Trabalho semelhante a este foi desenvolvido por Heagy (1988), nos Estados Unidos, possibilitando quantificar essas diferenças.

É de conhecimento geral que o profissionais de contabilidade serão muito afetados pela evolução da tecnologia de informação e, portanto, é necessário que o ensino contábil acompanhe essa evolução através da reestruturação do sistema de aprendizagem.

O que propomos neste trabalho é a identificação e quantificação das diferenças de ênfase dadas em diversos tópicos da área de Sistema de Informações (SI), abordados nos cursos de contabilidade, de tal modo que possam ser úteis na reestruturação dos cursos de Ciências Contábeis, para que possam atender às necessidades de capacitação profissional dos futuros contadores.

Segundo Castro (1978), "É necessário quebrar a tradição de redigir documentos em jargão legal, onde se descreve aquilo que gostaríamos que fosse a realidade, sem qualquer respeito pelo que de fato é a realidade, pelo que é refratário à mudança e sem a astúcia de descobrir os pontos onde o processo é manipulável". Isso demonstra que qualquer contribui- ção deve passar pela descrição e conhecimento da realidade.

A justificativa para este trabalho pode ser resumida em três fatos:

1) É um dos primeiros trabalhos na comparação direta das respostas de acadêmicos e práticos em relação ao atendimento das necessidades dos contadores práticos em relação à área de Sistemas de Informações dos cursos de graduação em Ciências Contábeis no Brasil. Nos trabalhos de HEAGY e McMICKLE [1998], e STOUT e SCHWEIKART [1989] podemos constatar as diferentes ênfases dadas pelos acadêmicos e práticos. Isso evidencia a relevância deste trabalho.

2) Existem muitas discussões acerca do futuro dos profissionais de contabilidade e da reestruturação do ensino contábil para atender às atuais necessidades dos contadores práticos. Antes de tomar qualquer posição, é razoável verificar em que extensão essas mudanças são suportadas pelos acadêmicos e práticos.

3) Para as faculdades que estão reformulando os seus Currículos, este trabalho pode fornecer importantes subsídios .

A primeira parte deste trabalho descreve os problemas de conteúdo das disciplinas de Sistemas de Informação dos cursos de Contabilidade. A seguir, é descrita a metodologia utilizada para coletar os dados dos acadêmicos e práticos.

Segue uma breve descrição dos atributos dos acadêmicos e práticos, bem como os procedimentos estatísticos para análise dos dados coletados.

A etapa final contém os resultados desta análise e as possíveis explicações para as diferenças encontradas entre os acadêmicos e práticos.

Outras áreas da Contabilidade não foram abordadas e podem ser objeto de futuros trabalhos.

\section{O conteúdo dos cursos atuais}

As duas últimas reformas do Currículo de Ciências Contábeis no Brasil aconteceram em 1984 e 1994. A primeira não incluía qualquer disciplina de Informática ou Sistema de Informação nos cursos de Contabilidade. A reforma de 1994 incluiu o curso de Informática como disciplina da grade curricular. 
Ao analisar o atual Currículo das faculdades de Ciências Contábeis na região de Ribeirão Preto/São Paulo - Brasil, constatamos que as disciplinas referentes à área de Sistemas de Informações estão concentradas em:

- Informática geral - com carga horária que varia de 60 a 140 horas

Algumas faculdades oferecem ainda as disciplinas:

- Sistemas de Informações Contábeis/Gerenciais - com carga horária de 30 a 60 horas

- Tópicos Avançados de Informática aplicados à Contabilidade - com carga horária média de 60 horas

As disciplinas de Contabilidade Introdutória e Auditoria são estritamente manuais (sem o uso de sistemas informatizados) com poucas exceções, embora já existam alguns trabalhos comprovando o enriquecimento do ensino contábil por meio do uso de sistemas computacionais, como podemos constatar em: GOOSEN e KUSEL [1984], MARTIN [1986], FETTERS e MCKENZIE e CALLAGHAN [1981], ARMITAGE e BORITZ [1988] , SMITH e MCDUFFIE [1988].

A falta de concordância por parte dos acadêmicos e práticos em relação ao conteúdo das disciplinas de "SI" repete aqui no Brasil o trabalho de HEAGY e McMICKLE [1988] . Acrescente-se a este fato a falta de literatura de "SI", em português, destinada aos estudantes de Ciências Contábeis.

Em função das mudanças significativas no modo de trabalhar dos contadores, decorrentes do impacto da informatização, a mudança nos Currículos dos cursos de Ciências Contábeis é necessária e urgente.

Um caminho a ser percorrido é aprender com os práticos quais os conteúdos da área de "SI" seriam necessários para atender às necessidades do contador no mercado. Conhecendo as necessidades dos contadores e as áreas abordadas pela academia, poderemos identificar as possíveis diferenças entre estes dois grupos e determinar o conteúdo apropriado para a área de Sistemas de Informação do curso de Ciências Contábeis.

O presente trabalho atualiza e estende as investigações prévias e engloba um enfoque regional, com o objetivo inicial de atender às necessidades específicas dos contadores da região do Estado de São Paulo - Brasil.

\section{Hipótese}

A hipótese deste trabalho é que existe diferença na ênfase do ensino e a prática contábil. As definições operacionais utilizadas foram obtidas através de um critério de ênfase adotado ao utilizar uma escala do tipo Likert de 7 pontos variando de extrema importância até mínima importância. A abordagem metodológica foi a empírico-analítica através da coleta, tratamento e análise dos dados quantitativos.

\section{Método da Pesquisa}

A investigação será feita com a participação dos professores das faculdades de Contabilidade do Estado de São Paulo/Brasil e com a colaboração dos contadores filiados ao Conselho Regional de Contabilidade do Estado de São Paulo/Brasil - região de Ribeirão Preto , acerca do conteúdo das disciplinas de Sistema de Informação ministradas nos cursos de Ciências Contábeis, para determinar os seus sentimentos em relação à preparação dos graduandos para o desempenho de suas atividades profissionais contábeis.

Os pesquisadores desenvolveram e pré-testaram um questionário desenvolvido para obter as opiniões dos acadêmicos e práticos em um conjunto de assuntos pertinentes à área de Sistemas de Informação. $O$ pré-teste foi feito com 25 práticos e 5 professores. Algumas alterações ocorreram nesta fase, dando origem ao questionário final, composto por 33 questões.

\section{Questionário}

Um questionário foi desenvolvido com 9 tópicos que poderiam ser ministrados no curso de Ciências Contábeis na área de Sistemas de Informação. Os tópicos foram selecionados através de extensa pesquisa bibliográfica que inclui livros e artigos utilizados no curso de Ciências Contábeis e pelos profissionais e professores de Contabilidade. São eles:

- Contabilidade Manual

- Sistemas de Informação Contábil

- Programas Aplicativos

- Sistemas Integrados

- Desenvolvimento de Sistemas

- Fundamentos de Computadores

- Internet e Comércio Eletrônico

- Auditoria de Computadores

- Projeto, programação e implementação de Sistemas 
Estes tópicos originaram 34 questões que foram pré-testadas antes de sua aplicação final .

O questionário foi elaborado na forma de uma escala tipo Likert com 7 graduações: mínima importância, pouca importância, abaixo da média de importância, importante, acima da média de importância , muita importância e extrema importância.

\section{Pré-teste}

Um pré-teste foi conduzido para determinar se o instrumento estava capturando o fenômeno desejado pelos pesquisadores e para ter uma maior certeza de que os aspectos importantes do ensino contábil não seriam omitidos.

O questionário foi aplicado em uma amostra de 25 alunos do MBA-Controladoria da FUNDACE-FEARP/USP/BRASIL para verificar a sua validade inicial. Com o resultado da aplicação do pré-teste, obtivemos a confiabilidade (internal consistency reliability) inicial através do alfa de Cronbach e da matriz de correlação calculada pelo SPSS $\AA$. O perfil dessa amostra compreende contadores que atuam em escritórios contábeis e profissionais liberais. Alguns professores foram incluídos na amostra para representar a academia.

O coeficiente interno de confiabilidade (alfa de Cronbach) obtido foi de 0.9094 , que é considerado muito bom de acordo com os padrões existentes. Em seguida, foram adotados dois critérios para análise dos resultados obtidos: (a) tabela do corrected-itemtotal-correlation e (b) os valores da matriz de correlação para verificar se alguns itens do questionário deveriam ser eliminados para melhorar a sua confiabilidade. Em decorrência desses critérios acima, o questionário foi reformulado para se obter maior validade. $O$ resultado final foi uma escala de 33 questões, sendo que uma delas foi eliminada.

\section{Amostra dos Acadêmicos}

O questionário foi enviado aos acadêmicos das 86 Faculdades de Ciências Contábeis do estado de São Paulo (Lista fornecida pelo CRC- Conselho Regional de Contabilidade -SP) com o intuito de obter o grau de ênfase dado a cada tópico. O conjunto enviado aos coordenadores dos Cursos de Ciências Contábeis consistia de uma carta de apresentação e cerca de 6 questionários com carta resposta pré-paga. No questionário indicava-se também a possibilidade de obter o questionário e enviar as respostas pela Internet.

Para cada Faculdade/Universidade foi feito um contato com o coordenador no sentido de solicitar uma colaboração no projeto. Em seguida foi enviada uma carta ao coordenador do curso de Ciências Contábeis, solicitando o preenchimento do questionário por pelo menos três (3) professores de cada faculdade, oriundos das seguintes áreas :

- Contabilidade Introdutória

- Informática

- Auditoria

Quinze dias após o envio dos questionários, os coordenadores foram novamente contactados para confirmar o seu recebimento. Novos questionários foram enviados para aqueles que declararam não ter recebido a pesquisa.

Uma nova remessa foi enviada após 3 meses da primeira remessa para as Faculdades que não enviaram os questionários preenchidos. Retornaram 30 questionários, sendo que 1 foi eliminado por preenchimento parcial de dados.

O total de respostas válidas foi de 71 contadores acadêmicos.

\section{Amostra dos Práticos}

A mesma versão enviada para os acadêmicos foi enviada para os práticos do Estado de São Paulo Brasil para obter o grau de ênfase percebida nos tópicos descritos que melhor os preparam para sua carreira como profissional contábil. O questionário indicava também a possibilidade de obter e enviar as respostas pela Internet.

A amostra consistiu de cerca de 800 questionários enviados aos contadores filiados ao CRC-SP (Conselho Regional de Contabilidade). Os questionários foram enviados pelo próprio CRC e foi incluída uma carta de apresentação e um envelope com carta resposta pré-paga. Nesta primeira etapa foram obtidas 100 respostas iniciais.

Posteriormente foi feito um novo trabalho com o auxílio de uma lista telefônica comercial pela qual foram feitos contatos telefônicos com dois grupos: os escritórios de contabilidade e as empresas. 0 objetivo dessa etapa foi o de enviar novamente um segundo questionário aos contadores filiados ao CRC-SP (segunda remessa) com a devida concordância do conselho. Pela pesquisa constatou-se que 
a maior parte das pequenas e médias empresas pesquisadas possui contabilidade terceirizada.

Nesta segunda etapa foram enviados mais 150 questionários pelo correio com um envelope de carta resposta pré-paga, totalizando 950 questionários para 800 contadores (alguns receberam mais de um questionário). Uma semana após o envio, os contadores foram novamente contactados para confirmar o recebimento desta segunda remessa.

Houve retorno de 209 questionários do total de 950 enviados, sendo que 9 foram eliminados por preenchimento parcial.

Para os respondentes práticos as respostas válidas foram em número de 200 , as quais, somadas às respostas dos acadêmicos, totalizaram 271 .

\section{ATRIBUTOS DOS RESPONDENTES}

\section{Acadêmicos}

A amostra dos 71 acadêmicos indicou que 38\% dos respondentes possuem entre 40 e 50 anos de idade, e $29 \%$ entre 30 e 40 anos.

Desses respondentes, $41 \%$ têm entre 10 e 15 anos de experiência na profissão contábil e 31\%, além de ministrar aulas em Faculdades e Universidades, são diretores de empresas.

Quanto à formação acadêmica, 43,6\% possuem Especialização (Lato Sensu) e $38 \%$ concluíram o Mestrado. Cerca de 35,2\% dos acadêmicos afirmam ter acima de 5 anos e até 10 anos de experiência na utilização de microcomputadores.

Com relação aos conhecimentos específicos na área de Sistemas de Informações, encontramos os seguintes resultados:

- $84,5 \%$ possuem conhecimentos em Sistemas Contábeis Computadorizados,

- 33,8\% possuem conhecimentos de sistemas integrados ERP (Enterprise Resource Planning),

-15,5\% possuem conhecimentos de Sistemas Especialistas (SIE, SIG, OLAP, Data Mining, Data Warehouse),

- 45\% possuem conhecimentos de Banco de Dados,

- 95,7\% possuem conhecimentos de Planilhas de Cálculo,

- $91,7 \%$ possuem conhecimentos de Navegadores (browser) de Internet,

-11,2\% possuem conhecimentos de Pacotes Estatísticos (SPSS e outros).

\section{Práticos}

Dos contadores profissionais (não professores) que responderam ao questionário, 47,5\% atuam na Contabilidade Tributária, $62,5 \%$ na Contabilidade Fiscal e 31,5\% em Controladoria. Dessa amostra, 83\% são do sexo masculino, enquanto $17 \%$ são do sexo feminino. Dos práticos 37,5\% possuem entre 30 e 40 anos e $24,5 \%$ entre 40 e 50 anos.

Cerca de $25,5 \%$ dos práticos possuem acima de 10 anos e até 15 anos de experiência na profissão, e $24 \%$ possuem acima de 20 anos de experiência. Quanto aos cargos ocupados dentro de empresas, $31 \%$ são diretores ou proprietários, $26 \%$ são gerentes, $12 \%$ supervisores e $10,5 \%$ auxiliares.

Quanto à formação acadêmica, cerca de 73,5\% possuem como última formação acadêmica concluída a graduação, 16\% fizeram Especialização (Lato Sensu) e $8 \%$ MBA, sendo apenas $2 \%$ compostos de Mestres e $0,5 \%$ de Doutores.

Cerca de $25,5 \%$ dos práticos possuem acima de 5 anos e até 10 anos de experiência em computadores e $25,5 \%$ de 10 a 15 anos de experiência.

Quanto à experiência em aplicativos específicos, tivemos a seguinte distribuição:

- Sistemas Computadorizados 86,5\%,

- ERPs 13\%,

- Pacotes Estatísticos 2\%,

- Planilha de Cálculo 78\%,

- Banco de Dados 25\%,

- Sistemas Especialistas 2,5\%,

- Navegadores Internet 75,5\%.

\section{Análise dos dados}

A razão entre o número de respondentes e o número de itens na escala foi de 7:1 que é considerada adequada e está próxima de 10:1 considerada ideal por KERLINGER [1978].

A medida de confiabilidade utilizada na amostra final foi o Alfa de Cronbach pelo qual obtivemos para os 33 itens um valor de 0,93 bem acima dos 0.70 descritos por CHAU [1999] como valor mínimo aceitável.

O teste " $\mathrm{t}$ " para amostras independentes foi utilizado para comparar médias dos grupos para suportar a hipótese de que não existem diferenças significativas entre os acadêmicos e os práticos com relação à ênfase dada a diversos tópicos de sistemas de informação nos cursos de graduação em contabili- 
dade. Os dados da amostra foram testados e tinham uma distribuição normal.

Uma vez que o teste não mostra a direção em que os grupos diferem, a média do grupo em relação ao grau de ênfase foi comparada. A média juntamente com o ranking dos tópicos também ajudou a explicar as diferenças entre os grupos. O nível de significância utilizado foi de 0,05.

\section{RESULTADOS}

A hipótese de que não existe diferença significativa na ênfase entre os acadêmicos e práticos em relação a diversos tópicos na área de Sistemas de Informação nos cursos de graduação em contabilidade foi aceita por 31 dos 33 tópicos.

Os práticos e acadêmicos diferem significantemente com relação ao grau de ênfase em apenas 2 dos 33 tópicos. A tabela 1 mostra os 2 tópicos em que isso ocorre (Q2 e Q4). O teste "t" foi utilizado para determinar a diferença significativa entre os dois grupos.

Como não existe diferença significativa entre os dois grupos em 31 dos 33 tópicos, podemos afirmar que os acadêmicos compartilham opiniões semelhantes em relação à maioria dos tópicos selecionados.

Por meio da análise dos dois tópicos em que existem diferenças significativas entre os dois grupos, podemos derivar informações relevantes para o ensino contábil.

O grupo acadêmico demanda uma ênfase maior em "Elaborar demonstrativos de forma manual " (Q2) e os práticos dão maior ênfase no tópicos : "Desenvolver sistemas de informações" (Q4).

Q2 indica que os acadêmicos ainda acreditam que a educação contábil deve passar pelo processo manual durante a fase de aprendizado. Acreditamos que isso deriva de alguns fatores como: falta de recursos na escola para desenvolver sistemas que poderão processar as demonstrações automaticamente e/ou que as atividades em muitas pequenas empresas ainda demandam que o processo seja feito manualmente.

A maior surpresa foi a ênfase dos práticos no tópico “ Desenvolver sistemas de informações " (Q4). Esses tópicos demandam um conjunto de conhecimentos que são comuns na área de Informática e que não estão presentes no Currículo de Ciências
Contábeis. Acreditamos que isso decorra do papel crescente do contador nas empresas. Se os contadores se tornarem mais ativos no processo de desenvolvimento de sistemas, o sistema final resultante tem maiores chances de atender às suas necessidades e torna-los um elemento chave no processo de gestão da empresa. Os acadêmicos, por outro lado, dão menores ênfases a esse tópico devido à ausência de recursos de hardware, software e equipe de apoio.

Analisando o ranking entre os acadêmicos e práticos verificamos que existem muitas semelhanças com exceção das questões Q3,Q16,Q17 e Q27. Q3 refere-se a "Projeto de Sistemas de Informação " e o ranking foi de 13 para os acadêmicos e 19 para os práticos. O resultado era esperado, uma vez que isto é uma atividade pouco comum entre os práticos. Q16 diz respeito ao uso do ERP como usuários. A maior ênfase dada pelos acadêmicos foi dada devido ao crescimento muito grande de empresas implementando ERP no Brasil, o que pode ser uma oportunidade à classe contábil. Q17 se refere à configuração dos sistemas ERP e foi melhor pontuada pelos práticos. Isso pode indicar que os práticos estão visualizando que será necessário customizar o ERP na empresa para atender às suas necessidades, o que pode ser realizado pelos próprios contadores. Q27 diz respeito à “ auditoria em volta do computador" e obteve uma diferença de 9 pontos e pode significar que os acadêmicos estão preocupados com uma auditoria de baixo custo e que foca na confiabilidade nos controles dos usuários e não nos controles dos computadores, situação comum ainda nas empresas de pequeno-médio porte no Brasil.

Os acadêmicos deram igualmente a maior importância ao tópico "Sistemas Integrados de pequeno porte". A menor importância dada pelos acadêmicos foi a de desenvolver Sistemas de Informação" enquanto que para os práticos a menor importância foi "Processar transações manualmente".

\section{DISCUSSÕES E CONCLUSÕES}

As diferenças de ênfase dadas aos tópicos de Sistemas de Informação nos cursos de Ciências Contábeis selecionados neste estudo poderão provocar uma discussão sobre a necessidade de 
reestruturação do ensino superior em Contabilidade, de tal modo a preparar os futuros profissionais em sua carreira contábil.

Apenas dois tópicos tiveram diferenças significativas em relação à média dos dois grupos, o que pode mostrar que os dois grupos estão sintonizados com relação à área de Sistemas de Informações. Uma vez que a educação contábil não está atendendo às necessidades dos práticos, surge a necessidade de reestruturação do Currículo Contábil.

Já que as ênfases dadas pelos dois grupos são similares, surge a pergunta: Por que não ocorrem as mudanças necessárias? Talvez isso decorra da velo- cidade do processo de mudança no ensino superior contábil no Brasil. Mesmo após um consenso entre os dois grupos interessados, a mudança é lenta e gradual.

As experiências dos práticos que estão atuando em um mercado muito competitivo e evoluindo tecnologicamente em um ritmo acelerado podem fornecer subsídios relevantes para a melhoria do ensino contábil. As mudanças do ensino são de responsabilidade da academia e devem levar em conta não só o Currículo, mas também o método de ensino, padrões e procedimentos locais além do suporte da faculdade para as mudanças necessárias.

\section{REFERÊNCIAS BIBLIOGRÁFICAS}

American Accounting Association, Committee on the future Structure, Content, and Scope of Accounting Education, "Future Accounting Education: Preparing for the Expanding Profession", Issues in Accounting Education (Spring 1986), pp. 172.

ARMITAGE, H.M., Boritz, J.E., Integration computers into the accounting curriculum, Issues in Accounting Education, pp. 86-99.

CASTRO, C.M. A prática da pesquisa, McGraw-Hill do Brasil, São Paulo, Brasil, 1978

GOOSEN, K.R., Kusel, J., Integrating Microcomputer Use Into na Information System Course, Issues in Accounting Education, pp. 77-86

KERLINGER, F.N., Foundations of Behavioral Research. Hlot, Reinehart and Wiston Inc, 1964.

HEAGY, C.D., McMickle, P.L., An Empirical Investigation of the Accounting Systems Course: Academic Practice Versus Practioners Needs, Issues of Accounting Education
FETTERS, M., McKenzie, Callaghan, D., Does Computer Hinder Accounting Education? An Analysis of Some Empirical Data, Issues in Accounting Education, pp 76-85.

MARTIN, J.R. , Dedicated Miscompute Software for Enrichment of cost and Managerial Accounting Education, Issues in Accounting Education, pp. 361-372

SMITH, L.M., McDuffie, Using Expert System to Teach Accounting for Business Combination, Expert Systems with Application, vol 10, n.2, pp. 181-191, 1996.

STOUT, D.E, Schweikart, J.A., The Relevance of International Accounting to the Accounting Curriculum: A Comparison of Practitioner and Educator Opinions, Issues in Accounting Education, Vo. 4 No 1, Spring 1989.

WILLIAMS, D.Z., The Challenge of Change in Accounting Education, Issues in Accounting Education, Vol. 6, No. 1, Spring 1991. 